\title{
O uso de narrativas como método para a avaliação da compreensão na afasia
}

\author{
Sabrine Amaral Martins \\ Pontifícia Universidade Católica (PUCRS), Porto Alegre, Rio Grande do Sul, Brasil \\ sabrine.martins@acad.pucrs.br
}

DOI: http://dx.doi.org/10.21165/el.v46i2.1514

\begin{abstract}
Resumo
Os déficits de compreensão causados pela afasia são frequentemente examinados por meio de tarefas de compreensão oral ou escrita de frases ou palavras isoladas. Todavia, essa avaliação não costuma contemplar os processos que subjazem a compreensão de narrativas, distintos dos processos de compreensão de palavras e frases. Por isso, as tarefas que envolvem narrativas devem ser complementares à avaliação da linguagem. Dessa forma, o objetivo deste trabalho é discutir o uso de narrativas como forma pertinente de avaliação da compreensão afásica. Para isso, discorre-se sobre os construtos avaliados como: níveis macroestrutural e microestrutural, influência do contexto e de diferentes níveis de complexidade nesses textos. Discute-se sobre a padronização dos textos para avaliação da compreensão em afásicos e a necessidade de adaptação à idade, escolaridade e cultura da população investigada.
\end{abstract}

Palavras-chave: avaliação; compreensão; afasia; narrativa.

\section{The use of narratives as a method for comprehension assessment in aphasia}

\begin{abstract}
Comprehension deficits caused by aphasia are commonly assessed by comprehension tasks of separate oral and written sentences or words. However, this assessment is not adequate to evaluate the underlying processes of narratives comprehension, which are different from words and sentences comprehension processes. For this reason, narrative tasks shall complement language assessment. Then, the aim of this article is to reflect about the use of narrative tasks as a pertinent way to evaluate aphasia comprehension. To do so, several constructs are discussed, such as: macrostructure and microstructure levels and the context and complexity influence levels on these narratives. In this paper, the author argues about a standardization of these narratives and their adaptation according to aphasics' age, education level and cultural background of people assessed.
\end{abstract}

Keywords: assessment; comprehension; aphasia; narrative.

\section{Introdução}

A experiência humana é influenciada pelo ato de compreender e produzir narrativas. Consideramos as narrativas pessoais dos outros fascinantes e nos engajamos em programações que envolvem narrativas como livros, peças de teatro, filmes. Nossa afinidade com estórias surge ainda na infância, quando nos deparamos com os livros de estórias e filmes infantis. Utilizamos a produção de narrativas para formar nossas biografias individuais. Selecionamos e organizamos memórias, construindo uma representação organizada e coerente de nós mesmos através delas (GERGEN, K.; GERGEN, M., 1988). A narrativa é um elemento de interação social e, portanto, essencial à nossa sobrevivência. Por isso, esse processo deve ser investigado, principalmente 
quando se trata de indivíduos com lesão cerebral cuja habilidade de compreensão de narrativas pode estar acometida.

$\mathrm{Na}$ ocorrência de acidentes vasculares encefálicos (AVEs), há sequelas graves. Especialmente no hemisfério esquerdo (HE), as consequências de um AVE podem incidir em problemas linguísticos, prejudicando a produção oral, a compreensão, as habilidades de leitura e escrita, podendo também acarretar problemas para entender substantivos, reconhecer palavras soltas, ler um jornal e/ou selecionar palavras, entender mapas e sinais de trânsito, identificar e nomear letras do alfabeto, usar um índice ou encontrar elementos usando categorias (onde olhar para encontrar determinado produto no supermercado), ler em voz alta, resumir, lembrar de eventos da narrativa após alguns parágrafos e compreendê-la além do nível superficial (ORTIZ, 2010). Todas as consequências dos AVEs e, particularmente, o prejuízo linguístico, têm enorme impacto, pois o indivíduo é privado quase totalmente da vida em sociedade.

As sequelas derivadas de lesões no HE são variadas. No Brasil, $38 \%$ dos casos apresentam afasia na fase aguda e $20 \%$ das vítimas continuam com alguma alteração de linguagem, como a afasia, após 6 meses do ocorrido (LIMA, 2009; MANSUR et al., 2002). A afasia é considerada uma modificação no conteúdo, na forma e no uso da linguagem e de seus processos cognitivos subjacentes, tais como memória e percepção (HALLOWELL; CHAPEY, 2008). Uma lesão em qualquer região do HE pode incidir em problemas de compreensão de ordem e modalidades distintas (DRONKERS et al., 2004). A compreensão oral, por exemplo, pode ser uma das sequelas mais devastadoras, podendo afetar a vítima funcionalmente, impedindo a realização de tarefas cotidianas, como atender o telefone. Essas pessoas podem conseguir participar de uma conversa informal com poucos sujeitos, utilizando gestos, pistas do contexto, expressões faciais em um ambiente com pouco ruído, porém, quando são requeridas mais competências, como inferências, há prejuízos. A compreensão leitora pode estar mais alterada que a oral, sendo acometida de diversas maneiras: ao entender palavras isoladas (em cardápios ou sinais de trânsito), frases (notas ou instruções), parágrafos (cartas, jornais e artigos de revistas) ou em textos mais extensos como livros. Ainda, há o impacto sob os outros construtos cognitivos, como memória, funções executivas e atenção, importantes para a compreensão. Esses danos na compreensão constituem uma barreira considerável para a reabilitação profissional das vítimas (SPRINGER, 2008).

Visando contribuir para a melhoria na qualidade de vida desses indivíduos, é imprescindível que se discuta o papel dos meios de avaliação e posterior tratamento dessas pessoas. As baterias utilizadas não abarcam os processos subjacentes à compreensão de narrativas. Sabe-se que a melhoria nos processos de compreensão de textos em geral pode contribuir para um aumento de qualidade de vida dos indivíduos com afasia, portanto, se faz necessária. Por essa razão, o presente trabalho tem por objetivo discutir o uso de narrativas como forma pertinente de avaliação da compreensão afásica. Assim, discorre-se sobre os construtos normalmente avaliados por meio das narrativas, tais como: níveis macroestrutural e microestrutural dos textos, influência do contexto e de diferentes níveis de complexidade na compreensão desses textos. Ainda, ressalta-se a importância de uma padronização dessas tarefas para a avaliação da compreensão em afásicos e a necessidade de adaptação à idade, escolaridade e cultura da população investigada. Para isso, será realizada uma reflexão acerca dos processos de compreensão de palavras e frases isoladas em comparação com as narrativas, meios de 
avaliação da compreensão nas baterias para afasias, tarefas requeridas para a verificação da compreensão das narrativas.

No estudo longitudinal de Mckevitt et al. (2011), 23\% dos indivíduos com lesão no HE (afásicos e não-afásicos) reportaram dificuldades de compreensão. Eram prejuízos para entender palavras isoladas em cardápios e sinais de trânsito, frases escritas em notas ou instruções, parágrafos, cartas, jornais e artigos de revistas e para compreender textos mais extensos, como livros. Embora a leitura integrada de um texto possa ser o último objetivo de um tratamento para a linguagem, poucos deles desenvolvem a leitura do indivíduo afásico até nível tão refinado. Em contrapartida, uma série de tratamentos trabalha com a leitura de palavras isoladas, havendo poucos dados sobre os ganhos desses tratamentos aplicados à leitura do dia a dia (WEBSTER et al., 2013).

\section{O que é uma narrativa?}

Texto não é uma mera unidade linguística (MARCUSCHI, 2014). Quando se define texto sob a ótica de critérios temáticos e transcendentes ao próprio texto, ele passa a ser conceituado como uma unidade comunicativa. A estrutura do texto implica no entendimento de elementos contextuais e contextuais, externos e internos a ele, respectivamente (MARCUSCHI, 2014). Para Halliday e Hasan (1976, p. 1-2), concebese texto como uma unidade em uso. Não deve ser visto como unidade gramatical, nem conceituado por seu tamanho. Para os autores, "texto é [...] uma unidade semântica: não uma unidade de forma e sim de sentido".

Os textos podem ser do tipo narrativo ou pertencer ao gênero narrativo. A tipologia textual concerne à estrutura do texto, sequência de ações e resolução do problema (JERÔNIMO, 2016). Já gênero compreende formas textuais escritas ou orais. Para Marchuschi (2008, p. 176), "todos os textos se realizam em algum gênero e todos os gêneros comportam uma ou mais sequências tipológicas". Considerando as afirmações acima, incluímos a noção de texto adotada para este trabalho em um texto do tipo narrativo por suas propriedades linguísticas e inserido no gênero narrativo por seus tipos relativamente estáveis de enunciados (JERÔNIMO, 2016).

Para Labov (1972, p. 290), uma narrativa é uma recapitulação textual da experiência temporalmente estruturada. Ela é dotada de identidades sociais, relações, processos linguísticos e cognitivos, fidelidade e verossimilhança. A narrativa é vista como um texto, pois ela é produto da interação humana no tempo, refletindo um passado e um futuro. Além disso, constitui configurações e reconfigurações do mundo e do que acontece nele e desse mundo emergem as estórias (BLOOME, 2003). Também por isso, a narrativa é definida como um evento e uma prática (BLOOME, 2003). Ela é concebida dessa maneira de acordo com o modo como as pessoas interagem entre si e nos significados e possibilidades criados a partir dela. Segundo Bloome (2003), a fronteira de uma narrativa não é a linguagem em si, mas sim a interação humana.

A discussão sobre a estrutura da narrativa primeiramente se concentrou na organização linguística dessa representação - como uma série de eventos são configurados para denotar verossimilhança da vida sociocultural, a experiência de catarse e a estética (BLOOME, 2003). No entanto, a estrutura da narrativa pode ser vista, paradoxalmente, como um reflexo e um modelo da experiência humana, desde que haja uma relação lógico-semântica entre ações e atuantes (ADAM, 1985, 2008). Para se ter 
uma narrativa coerente, é necessário que as ações dessa narrativa estejam conectadas por uma relação cronológica e lógica. Logo, ainda é preciso que ocorra uma mudança entre uma situação inicial e o estado final, sendo a conclusão dessa narrativa. Assim, o atuante deve atravessar a narrativa, unificando suas ações e realizando a mudança (ADAM, 1985). Para Adam (1991, p. 45), "enquanto unidade textual, toda narrativa corresponde, na verdade, idealmente, à definição mínima que podemos dar da textualidade: sequência de proposições ligadas progredindo para um fim”.

\subsection{A compreensão de narrativas e palavras isoladas/frases na afasia}

Compreender não demanda apenas decodificar a mensagem através de processos linguísticos, mas também utilizar recursos não linguísticos como a atenção e o conhecimento prévio para a interpretação (ULATOWSKA, 1981). Por isso, os processos cognitivos e linguísticos que subjazem a compreensão de palavras e frases parecem não ser os mesmos que subjazem a compreensão de textos.

A compreensão de palavras e frases nos afásicos costuma ser prejudicada por conta da anomia, caracterizada por um comprometimento em algum(s) dos níveis do processo de recuperação lexical (HOWARD, 2000). Da mesma forma, a pesquisa de Crutch e Warrington (2011) verificou que os déficits de compreensão de palavras poderiam ser advindos de danos parciais nas representações semânticas (CRUTCH; WARRINGTON, 2011). Os resultados apontaram padrões diferentes de compreensão de palavras e textos, sofrendo influências da categoria semântica e da frequência dos itens apresentados.

No nível frasal, pessoas com afasia tendem a ter dificuldades na compreensão de frases gramaticalmente complexas e reversíveis (como as passivas) quando apresentadas nas modalidades oral e escrita. A exemplo dessas dificuldades, encontra-se o estudo de Dede (2013), o qual comparou os efeitos de complexidade sintática na compreensão de frases na modalidade escrita e na modalidade oral em pessoas com afasia e controles saudáveis. O estudo mostrou que os indivíduos com afasia obtiveram escores variáveis nas tarefas que envolviam sentenças simplificadas sintaticamente, sugerindo que o aumento da quantidade de elementos linguísticos e a complexidade sintática poderiam causar um impacto na compreensão. Esse estudo apontou que os afásicos sofreram influência da frequência das palavras escritas, tornando a compreensão de palavras menos acurada do que a de compreensão de frases (DEDE, 2013).

Apesar da necessária capacidade de nomeação e da compreensão de sentenças para o indivíduo afásico, é inevitável apontar que a dificuldade de compreensão de um texto restringe a comunicação do indivíduo. As narrativas podem ser na forma oral, presentes no dia a dia. Elas são parte essencial da experiência humana, ajudando a organizar o pensamento, são recurso para a evocação das lembranças e ajudam a trazer à tona as memórias, visto que se tratam de sequência de ideias organizadas coesa e coerentemente (JERÔNIMO, 2012). Dessa forma, o prejuízo na compreensão de textos impacta negativamente a vida social e profissional do afásico.

A compreensão de narrativas demanda muito mais processos do indivíduo (FERSTL et al., 2005). Os processos que envolvem a compreensão de narrativas são mais complexos do que os das palavras e frases, pois o significado de um texto acontece a partir do estabelecimento de relações de coerência implícitas ou explícitas entre as inferências realizadas pelo indivíduo (FARIAS; DIJK, 2000). No nível textual, há poucas 
evidências sobre a compreensão de textos quando se trata de estudos de grupo (CHERNEY, 2010). No estudo de Cherney (2004), o participante aprimorou a compreensão de textos, mas não houve evidência da efetividade do tratamento. Já o trabalho de Lott e Friedman (1999) aponta uma influência da frequência de leitura na habilidade de afásicos para compreender narrativas, além de ganhos no que tange à compreensão no nível de frases e de parágrafos (LOTT; FRIEDMAN, 1999).

Os indivíduos afásicos parecem compreender narrativas mesmo que dificuldades como a anomia estejam presentes. Assim, dois processos parecem subjazer a compreensão de narrativas por essas pessoas: construção da inferência e da macroestrutura. Para compreender um texto, é necessário inferir; é preciso combinar a informação explícita disponibilizada no texto com a informação de conhecimento de mundo do indivíduo. Depois, ainda é necessário extrair a macroestrutura do texto, que se refere ao significado global do tópico ou tema. Há dados apontando que a construção do nível macroestrutural do texto pode estar preservada (GLOSSER; DESER, 1991; HUBER, 1990; ULATOWSKA; CHAPMAN, 1991). Portanto, existe evidência disponível para ser utilizada nos tratamentos e recuperação da afasia.

Ainda, a compreensão de textos contempla mais regiões cerebrais do que a compreensão de palavras. Essa última requer um sistema distribuído que envolve as áreas clássicas perissilvianas entre o giro temporal superior, médio e córtex frontal inferior (MAGUIRE et al., 2000; FERSTL; VON CRAMON, 2001; FERSTL; GUTKHE; VON CRAMON, 2002; FERSTL et al., 2005; XU et al., 2005) ao passo que a compreensão de narrativas engaja mais regiões corticais. Dentre essas regiões, além dos lobos temporais anteriores (FERSTL et al., 2008), está o córtex orbitofrontal (XU et al., 2005). O córtex orbitofrontal, juntamente com regiões parietais, é responsável por integrar informações entre múltiplos sistemas cerebrais (BARBEY; COLOM; GRAFMAN, 2014), evidenciando esse sistema mais distribuído para a compreensão.

Apesar dos dados já descritos sobre o papel da compreensão de narrativas para a qualidade de vida do indivíduo afásico, ainda há mais pesquisas direcionadas para a compreensão de palavras e frases do que para narrativas. Esse fato acontece por muitas baterias de avaliação da afasia não abarcarem atividades com textos e somente com compreensão de palavras e frases curtas. Ressalta-se que a avaliação da compreensão de todos os itens da linguagem, em particular as narrativas, é importante para o tratamento e recuperação dos indivíduos afásicos, uma vez que as narrativas são mais utilizadas no dia a dia do que palavras e frases isoladas.

\subsection{Avaliação da compreensão de narrativas}

Existe uma variedade de instrumentos que avaliam a compreensão nos indivíduos afásicos. Essas baterias normalmente avaliam a compreensão oral e escrita de palavras, comandos, frases e, eventualmente, pequenas narrativas. Algumas baterias são mais frequentemente escolhidas pelos fonoaudiólogos e outras não possuem sequer versões adaptadas e validadas para outras línguas que não a língua inglesa. Nesta seção, algumas dessas baterias serão enumeradas e as tarefas que avaliam a compreensão afásica descritas.

A primeira bateria trata-se do Exame de Boston para o Diagnóstico da Afasia (Boston Diagnostic Aphasia Examination - BDAE: GOODGLASS; KAPLAN, 1995). Nessa bateria, está contido um dos testes mais usados para a avaliação do vocabulário, 
apesar das críticas que recebe constantemente: Teste de Nomeação de Boston. Nesse teste que compõe a BDAE, as figuras devem ser nomeadas pelo indivíduo e, após, ele deve apontar para as figuras faladas pelo avaliador, demonstrando compreensão. Além disso, o afásico deve derivar uma narrativa a partir da imagem que lhe é dada. Já na atividade de compreensão de frases, os indivíduos com afasia devem realizar os comandos dados pelo avaliador, embora esse meio de avaliação também receba muitas contrapartidas. Conforme Novaes-Pinto (1999), essa ordem não é dada naturalmente, destituindo o sentido cultural ou pragmático. Ainda no mesmo exame, respostas positivas ou negativas são requeridas para a avaliação da compreensão de frases. As opções distinguem-se semanticamente e também sofrem críticas. Além da compreensão de frases, a bateria avalia a compreensão de narrativas curtas. São dadas quatro narrativas com aproximadamente sete frases e 66 palavras, com um tema humorístico. Novamente, nas histórias, há situações superficiais que podem não ser adequadas para a avaliação da compreensão, visto que as perguntas após as narrativas são de respostas "sim" e "não". Sob o olhar de Novaes-Pinto (1999), as perguntas não são apropriadas, pois as inferências não podem ser realizadas a partir das pistas fornecidas.

Uma outra bateria que também avalia a compreensão na afasia é o Teste de Rastreamento (Western Aphasia Battery - WAB: KERTESZ, 2007). As tarefas são referentes à Fala Espontânea (Conteúdo e Fluência), Compreensão Auditiva Verbal, Comandos Sequenciais, Repetição, Nomeação, Leitura, Escrita e Apraxia. Na compreensão auditiva, são feitas perguntas cujas respostas devem ser "sim" ou "não" e outras com respostas livres sobre o nome do indivíduo, profissão, local em que se encontram, dentre outros. O indivíduo pode responder verbalmente, com gesto ou piscando os olhos. Já a compreensão de palavras e comandos se dá mediante a realização do que é pedido, por exemplo, "toque seu nariz", "feche os olhos" etc. A WAB não apresenta avaliação de compreensão de textos.

A Avaliação psicolinguística do Processamento da Linguagem na Afasia (PALPA - Psycholinguistic Assessments of Language Processing in Aphasia: KAY; LESSER; COLTHEART, 1992) avalia a compreensão de frases simples e complexas. Os autores sugerem que, avaliando as frases complexas - como passivas e relativas -, podemos observar os problemas de compreensão. Os subtestes de compreensão da PALPA consistem em um conjunto de 60 pranchas, com três figuras cada, dentre as quais o sujeito deve apontar apenas uma, que esteja relacionada ao significado de uma sentença lida oralmente pelos avaliadores. Há críticas a respeito da natureza semântica dessas frases, já que as dificuldades de compreensão podem ocorrer devido à falta de realidade presente nas sentenças.

Especificamente para a compreensão de narrativas, há uma bateria denominada Teste de Compreensão de Discurso (Discourse Comprehension Test - DCT: BROOKSHIRE; NICHOLAS, 1993). A DCT avalia a compreensão de palavras isoladas e frases em textos. Ela avalia a compreensão e retenção das ideias principais e de detalhes em 10 estórias com perguntas de respostas "sim" e "não". As narrativas são sobre fatos do cotidiano e possuem tom humorístico. Elas foram controladas nos níveis de tamanho da narrativa, complexidade gramatical, dificuldade de audição e nível de informatividade. Ela permite a avaliação da compreensão de textos tanto escritos quanto orais e fornece informações importantes acerca do estado da compreensão afásica. Ela é feita em língua inglesa e não apresenta versões em outras línguas, como em português brasileiro. 
Como podemos notar, as tarefas que avaliam a compreensão de narrativas não são corriqueiras nas baterias para afasia. É comum essas tarefas constituírem-se de somente uma atividade ao longo de uma bateria inteira. E é mais frequente ainda que as narrativas sejam o estímulo antecessor para uma série de perguntas cujas respostas devem ser "sim" ou "não". De fato, são vistas limitações nas tarefas de compreensão de narrativas por indivíduos afásicos, o que faz mais urgentes as pesquisas sobre o tema e a consequente padronização de mais testes.

\section{O uso de narrativas para a avaliação do nível microestrutural e macroestrutural do texto}

Os estudos que tratam de compreensão de narrativas demonstram uma tendência à acurácia relacionada ao nível da macroestrutura textual em detrimento da microestrutura. Existem evidências sugerindo que a construção de macroestruturas do texto pode estar preservada (GLOSSER; DESER, 1991; HUBER, 1990; ULATOWSKA; CHAPMAN, 1994) na afasia. Para alguns pesquisadores, a macroestrutura e a microestrutura de uma narrativa ocupam níveis distintos de representação mental, sendo o nível macroestrutural localizado em uma camada mais profunda e o nível microestrutural em uma mais superficial. Considerando que a macroestrutura é propriedade mais profunda, é bastante problemático identificar as manifestações linguísticas nesse nível no texto. Todavia, alguns indícios dessa representação mental podem ser identificados nas tarefas que requerem a criação de títulos dos textos e resumos, estruturas possivelmente preservadas na ocorrência de afasia. Alguns trabalhos que ilustram essa situação são as pesquisas de Wegner, Brookshire e Nicholas (1984) e Brookshire e Nicholas (1984).

O trabalho de Wegner, Brookshire e Nicholas (1984) verificou a compreensão oral de ideias principais e detalhes, ou seja, macroestrutura e microestrutura, em narrativas coerentes e incoerentes. Eles acreditam que é necessário entender as ideias principais para formular um modelo mental coerente de um texto. Os autores prepararam dez parágrafos sobre atividades diárias, aplicando índices Flesch de leiturabilidade. Foram avaliados pelo Dale-Chall Readability Formula (DALE; CHALL, 1948), classificando os textos em nível de $7^{\text {a }}$ série ou inferior. Todos variaram de 99 a 110 palavras, com uma média de oito ou nove frases, o número médio de palavras por sentença variou de 110 a 130 . Metade dos parágrafos era coerente e metade incoerente, sendo os incoerentes com uma mudança de tema a partir da quarta ou quinta frase. Os textos foram gravados por uma voz masculina, em ambiente próprio, com uma média de 128 palavras por minuto. Os participantes eram conduzidos a uma sala silenciosa, onde poderiam ouvir a gravação. Eram dados dois cartões, com as palavras "sim" e "não". Após a audição, os participantes deveriam responder seis perguntas positiva ou negativamente. Três das perguntas tratavam da ideia principal do texto e três dos detalhes. Foi realizada uma sessão de treinamento antes da aplicação da tarefa para verificar o entendimento da instrução. Não era permitido ao participante ouvir a pergunta novamente, porém se fosse necessário um tempo maior do que cinco segundos para a escolha da resposta, tal tempo era disponibilizado.

Os resultados da pesquisa de Wegner, Brookshire e Nicholas (1984) mostraram que tanto os indivíduos afásicos quanto os controles obtiveram maiores escores nas perguntas relativas às ideias principais. A (falta de) coerência parece não ter afetado o 
desempenho dos grupos para a compreensão das ideias principais. Todavia, a coerência parece ter influenciado a compreensão dos detalhes, visto que os indivíduos afásicos tiveram uma performance menos acurada na compreensão de detalhes nos parágrafos incoerentes. Os autores discutem esse achado atentando para a facilidade e dificuldade de retenção dos detalhes, isto é, detalhes diferentes possuem efeitos distintos na compreensão. Eles salientam que detalhes como números, incluindo horas, locais com nomes próprios, meses, estações do ano, partes do dia, em especial à noite, dias da semana e detalhes muito misturados foram os que mais causaram problemas de compreensão.

Já a investigação de Brookshire e Nicholas (1984) observou a compreensão e a retenção de ideias principais de parágrafos orais em indivíduos com afasia. Os autores queriam destacar as importantes diferenças que subjazem a compreensão de sentenças simples e de textos dados direta e indiretamente. No texto, o contexto auxilia o ouvinte a deduzir o significado pretendido ou a resolver frases ambíguas, fato que não ocorre quando há apenas frases isoladas. A tarefa utilizada pelos autores constituía-se de seis parágrafos narrativos escritos. Eles variaram de 97 a 110 palavras e tinham entre oito e nove frases. Da mesma forma que o estudo de Wegner, Brookshire e Nicholas (1984), o índice de leiturabilidade Dale-Chall Readability Formula (DALE; CHALL, 1948) também foi usado, classificando os textos em nível de $7^{\mathrm{a}}$ série ou inferior. Cada parágrafo continha quatro ideias principais com dois detalhes associados a cada uma delas. Para cara parágrafo, oito pares de frases foram escritas, sendo que, em cada par, uma frase era verdadeira e outra falsa, permitindo uma contradição. Metade das frases avaliava as ideias principais e o restante, os detalhes. Na realização da tarefa, os indivíduos afásicos ouviam os parágrafos em uma sala silenciosa e eram instruídos a mostrar um dos cartões que tinham ganhado para cada frase ouvida. Um dos cartões tinha um rosto feliz, representando a resposta verdadeira e o outro cartão tinha um rosto triste, representando a resposta falsa. Foram feitos cinco parágrafos-teste e dados dez segundos de intervalo silencioso entre cada um.

Os indivíduos afásicos apresentaram mais erros nos itens do teste do que os outros participantes da pesquisa. Todavia, os resultados sugerem que os afásicos utilizaram os mesmos recursos que os indivíduos saudáveis para a compreensão de narrativas orais. Eles preferiram ideias principais aos detalhes, tendendo a uma maior acurácia nos elementos do nível macroestrutural do que no microestrutural. Os autores discorrem sobre esse achado destacando as diferenças qualitativas entre os distintos tipos de afasia. Para eles, o tipo de afasia parece ter influenciado a performance na compreensão dos textos. Os indivíduos com afasia fluente foram os menos acurados nas tarefas. Já aqueles com afasia mista e não-fluente apresentaram um melhor desempenho. Eles destacam que o tipo de afasia poderia prever a performance linguística do indivíduo. O principal resultado desta pesquisa é que todos os grupos participantes foram mais acurados para as perguntas de macroestrutura, independente das ideias principais serem dadas diretas ou indiretamente.

Os dados das duas pesquisas sugerem que os afásicos compreendem oralmente melhor as ideias principais do que detalhes em narrativas. Isso indica que os indivíduos lesados podem utilizar as mesmas estratégias para a compreensão oral que os indivíduos saudáveis, pelo menos para elementos do nível macroestrutural. Os afásicos parecem procurar, identificar e lembrar das informações necessárias para manter o texto globalmente coerente, exatamente como os saudáveis o fazem, apontando para uma tendência de acurácia no nível macroestrutural. No que concerne ao nível microestrutural, 
os autores destacam que um importante achado é que alguns detalhes são de mais difícil retenção do que outros. Independente do grupo, detalhes misturados foram problemáticos. Os autores afirmam que as diferenças de compreensão entre os indivíduos saudáveis e afásicos podem estar na quantidade de erros e não na qualidade ou nos tipos de erros.

\section{O uso de narrativas para a avaliação da influência do contexto}

A influência do contexto também tem sido alvo de investigações na compreensão em afasia. Quanto maior o fornecimento de pistas contextuais tanto linguísticas como visuais, mais o indivíduo afásico poderá se beneficiar para a compreensão de um texto, seja ele oral ou escrito (KUMAR; GOSWAMI, 2012). Dentro desse nicho, destacam-se os estudos de Germani e Pierce (1992) e Dietz (2008), que avaliam a compreensão de textos em indivíduos afásicos a partir de narrativas e informações contextuais, respectivamente.

A presença de informações contextuais como símbolos, fotos, desenhos pode auxiliar na compreensão leitora de indivíduos com afasia (ULATOWSKA et al., 1999). $\mathrm{O}$ encadeamento de ações das narrativas propicia uma redundância contextual, que pode auxiliar na apreensão da macroestrutura de um texto, fornecendo pistas para sua interpretação. A redundância contextual abrange a repetição de termos ou de seus sinônimos e o isolamento de estruturas pré-determinadas para a transmissão da mensagem de um texto. Além desses recursos, existem ainda as instâncias da redundância gramatical como a ordem das palavras nas sentenças, o emprego de pronomes, dos objetos diretos e indiretos bem como de desinências verbais e nominais (WIT; GILLETTE, 1999). As informações contextuais funcionam como pistas para a compreensão da mensagem transmitida (GERMANI; PIERCE, 1992).

O estudo de Germani e Pierce (1992) teve como objetivo verificar a compreensão de afásicos em sentenças passivas previsíveis presentes ou ausentes em narrativas curtas. Os autores sugerem que, tal qual ocorre na compreensão de texto oral, a inserção da informação alvo em um contexto, no caso a narrativa, provê um ambiente linguístico favorável para a interpretação daquela informação. Para a pesquisa, foram elaboradas, a partir de um estudo piloto, 24 narrativas com cinco frases cada, vocabulário comum e estrutura sintática relativamente simples. A estrutura passiva alvo era colocada em quatro condições: 1) isolada sem contexto, 2) precedida de uma narrativa previsível, 3) precedida de uma narrativa não previsível e 4) não apresentada. Os textos eram apresentados aos indivíduos afásicos em forma de cartões, com grafia ampliada. Após a leitura silenciosa da narrativa, os participantes deveriam virar o cartão, ler a pergunta e apontar uma das duas respostas disponíveis escritas no cartão. Nenhuma outra forma de resposta era aceita e não era possível aos participantes retornar para a narrativa para sanar dúvidas. Os resultados da pesquisa apontaram que a existência do contexto, como uma narrativa precedendo uma frase-alvo, não melhora a habilidade de processar informações pelos afásicos. Ao invés disso, lhes permite ignorar a estrutura alvo e ater-se ao contexto (HUBER, 1990; GERMANI; PIERCE, 1992).

O estudo de Dietz (2008) avaliou o impacto da compreensão afásica com o auxílio de três níveis de contexto visual - a) narrativas com cenas altamente contextualizadas, b) narrativas com cenas pouco contextualizadas e c) textos com fotos descontextualizadas. Foram utilizadas no total 12 cenas: três sem contexto, três muito contextualizadas e três pouco contextualizadas. As cenas muito contextualizadas 
tratavam-se de fotografias de pessoas interagindo entre elas em um ambiente natural e uma ação central na cena. Já as pouco contextualizadas eram fotos sem ação central e interação limitada ou absente entre as pessoas e o ambiente natural. Os textos narrativos foram criados a partir das fotos. Eles foram equilibrados por número de palavras, palavras por frase, caracteres por palavra, índice de leitura Flesch Reading Ease (FLESCH, 1948) e índice Flesh-Kincaid Grade Leval (FLESCH, 1948). A primeira narrativa tinha 107 palavras, 10.7 palavras por frase, 3.9 caracteres por palavra e índices de leitura Ease e Flesch-Kincaid 95.5 e 2.5. A segunda narrativa tinha 100 palavras, dez palavras por sentença, 4.2 caracteres por palavra e índices de leitura Ease e Flesch-Kincaid 95.1 e 2.4. Já a terceira narrativa possuía 101 palavras, 10.1 palavras por frase, 3.8 caracteres por palavra e índices de leitura Ease e Flesch-Kincaid 96.9 e 2.2, respectivamente. A pesquisadora ainda utilizou o índice de dependência de passagens para a confecção das narrativas. O material foi impresso em fonte Arial 18, com espaço duplo entre linhas, em forma de cartaz. Antes das perguntas de compreensão, o examinador lia a narrativa para o participante. Neste estudo, os afásicos tiveram um melhor desempenho na compreensão de narrativas cujo contexto era dado, independente de grau de relação entre as cenas e a narrativa.

Os estudos de Germani e Pierce (1992) e Dietz (2008) sugerem que as informações contextuais podem auxiliar na compreensão das narrativas, tornando os indivíduos afásicos mais acurados nas questões de compreensão. No primeiro estudo, os participantes se beneficiaram tanto das narrativas previsíveis quanto das não-previsíveis, não sendo encontradas diferenças relevantes entre essas variáveis. Durante a leitura das narrativas, os participantes se familiarizam com as personagens principais e as ações que vão acontecer. Nos momentos finais da narrativa, o participante já sabe quem está envolvido e o que ocorrerá. Nas frases não precedidas de narrativa, os participantes devem dividir sua atenção em determinar as personagens principais, a ação e a relação entre elas, tornando a compreensão mais difícil. No segundo estudo, embora mais acurado, não foram encontradas diferenças relevantes na acurácia dos participantes. Uma possível explicação para isso está relacionada à heterogeneidade existente entre eles, acerca das suas habilidades linguísticas anteriores ao acometimento.

\section{O uso de narrativas para a avaliação da complexidade}

Os trabalhos de Brennan, Worral e McKenna (2005) e Caplan (1990) observaram o efeito da complexidade sintática para a compreensão de afásicos. Ambos trabalhos destacaram que o material deve ter seu nível de complexidade, principalmente sintática, adaptado para uma maior acurácia da compreensão dos indivíduos afásicos. Brennan, Worral e McKenna (2005) verificaram a compreensão de afásicos em narrativas, simplificando o vocabulário e a sintaxe, comparando com dados de controle. Já o estudo de Caplan e Evans (1990) verificou os efeitos da estrutura sintática na compreensão discursiva.

Brennan, Worrall e McKenna (2005) observaram os efeitos de materiais aphasiafriendly na compreensão de indivíduos com afasia. Segundo os autores, os indivíduos afásicos poderiam compreender melhor os parágrafos que fossem elaborados especificamente para pessoas com afasia, ou seja, parágrafos com vocabulário simples, frases curtas, tipografia maior, espaço em branco entre linhas aumentado e auxílio de figuras. Para tal, os pesquisadores utilizaram uma bateria com 90 parágrafos, de uma série 
de leitura infantil da Associação de Pesquisa Científica (Scientific Research Associate SRA). Os parágrafos eram indicados para crianças de $5^{\mathrm{a}}, 6^{\mathrm{a}}$ e $7^{\mathrm{a}}$ séries e divididos em: 1) parágrafos-controle 2) parágrafos com vocabulário e sintaxe modificados; 3) parágrafos com tipografia modificada para fonte Arial 24; 4) parágrafos com espaço em branco entre linhas modificado para $7.7 ; 5)$ parágrafos fornecidos com figuras auxiliares e 6) parágrafos com todas as modificações anteriores.

No procedimento, os indivíduos afásicos deveriam indicar, dentre quatro alternativas, qual era a melhor opção de palavra ou frase para completar o final do parágrafo. Eles eram convidados a ler cada parágrafo silenciosamente ou em voz alta, quantas vezes precisassem. Após a leitura, deveriam apenas apontar a alternativa que melhor completasse o final do parágrafo. Nenhum feedback era dado sobre as respostas dos participantes, mas elas eram computadas no momento da aplicação. Se o examinador visse que o participante errara quatro respostas consecutivas de uma única condição, a aplicação era cessada. Não há menção ao tamanho dos parágrafos em termos de número de frases e palavras. Segundo os exemplos fornecidos no apêndice do artigo, pode-se afirmar que eles continham de uma a três frases, com 10-28 palavras no total.

A pesquisa de Caplan e Evans (1990) observou a influência da estrutura sintática na compreensão textual de afásicos. Além de um teste de compreensão sintática, os autores aplicaram um teste de compreensão de textos. O teste constituía-se de duas narrativas e dois contos populares. Todas as estórias eram aproximadamente iguais em tamanho, sendo o número de palavras entre 184 e 190; as frases eram classificadas em sintaticamente simples e complexas. Após a audição das estórias, 18 sentenças eram fornecidas ao participante. Este, por sua vez, deveria julgar se o que estava escrito havia acontecido na estória ou não. A estória só seria lida uma vez, embora as 18 sentenças pudessem ser repetidas. Antes do início do teste, cada participante tinha uma sessão de treino, com um parágrafo e duas sentenças do tipo verdadeira ou falsa. Nesta pesquisa, há poucas informações sobre os textos, não aparecendo uma descrição da complexidade e simplicidade sintáticas mencionadas.

Os estudos de Brennan, Worral e McKenna (2005) e Caplan e Evans (1990) enfatizam que os indivíduos afásicos têm mais acurácia na compreensão de textos quando há a simplificação do estímulo, frases mais curtas, sentenças afirmativas ao invés de interrogativas e negativas, uso de voz ativa ao invés de passiva, uso de discurso direto e de orações coordenadas. Além desses fatores, outros também influem na manutenção da complexidade para a compreensão afásica, como o caso do tamanho, espaçamento e fonte das letras, a presença de imagens e, no caso de material auditivo, estímulo auditivo sem ruídos, gravados em estúdio. Logo, pode-se afirmar que o material facilitado auxilia na compreensão.

\section{Sobre a necessidade de padronização e adaptação dos textos}

A partir dos textos analisados, pode-se dizer que há uma necessidade de padronização. As tarefas usadas para a avaliação da compreensão são bastante variadas. Nem todos os estudos mencionam a quantidade de frases, de palavras de conteúdo ou de caracteres das narrativas. Apenas Dietz (2008) menciona este último item. Além disso, não parece haver um controle de frases passivas e discurso direto nesses textos. Sabe-se que esses fatores podem influenciar a compreensão dos indivíduos afásicos. 
Os textos são formulados pelos pesquisadores ou extraídos de baterias ou compilações já existentes. Alguns retiraram as narrativas de livros infantis e outros escreveram baseando-se em fatos do dia a dia. Nem todas as pesquisas fornecem exemplos, por isso, há uma dificuldade em avaliar e replicar as tarefas e estímulos. Há uma falta de padrão do tamanho desses textos, que costumaram variar em torno das 100 palavras, na sua maioria. Há dados disponíveis sobre o efeito do tamanho das narrativas na compreensão dos indivíduos afásicos, textos longos são mais dificultosos. No entanto, não se sabe quais são os parâmetros para um texto longo. Portanto, por causa disso, ainda é preciso cautela para investigar a compreensão de narrativas em indivíduos afásicos.

As tarefas aqui apresentadas variaram entre uma e 90 narrativas. Algumas observaram índices de leiturabilidade como os índices Flesch (FLESCH, 1948) e DalleChall (DALLE; CHALL, 1948), já outras mencionam ter utilizado vocabulário e estrutura sintática simplificadas. O controle desses itens é de grande responsabilidade. É sabido a dificuldade inerente e as frustrações cabíveis aos indivíduos afásicos quando devem compreender textos muito longos (FERSTL et al., 2005). A atividade pode tornar-se cansativa, frustrante e pode ocorrer distração. Frases muito longas ou com estruturas muito complexas, como o caso das passivas, pode intensificar a dificuldade (BRENNAN; WORRAL; McKENNA, 2005). Abaixo, segue um quadro com as descrições das tarefas utilizadas.

Quadro 1. Descrição das tarefas

\begin{tabular}{|c|c|}
\hline Autores & Descrição das narrativas \\
\hline $\begin{array}{l}\text { Wegner; } \\
\text { Brookshire; } \\
\text { Nicholas (1984) }\end{array}$ & $\begin{array}{l}\text { Dez parágrafos sobre atividades diárias com índices de leiturabilidade de } 7^{\mathrm{a}} \text {. } \\
\text { série ou inferior. Variaram entre } 99 \text { e } 110 \text { palavras, com uma média de } 8-9 \\
\text { frases, sendo o número médio de palavras por sentença } 11 \text { a } 13 \text {. }\end{array}$ \\
\hline $\begin{array}{l}\text { Brookshire; } \\
\text { Nicholas (1984) }\end{array}$ & Seis estórias entre 97 e 110 palavras com $8-9$ frases, indicados para $7^{\mathrm{a}}$ série \\
\hline $\begin{array}{l}\text { Caplan; Evans } \\
(1990)\end{array}$ & $\begin{array}{l}\text { Quatro narrativas, sendo o número médio de palavras } 184-190 \text { e frases } \\
\text { classificadas em sintaticamente simples e complexas, indicadas para } 4^{\text {a }} \text { série. }\end{array}$ \\
\hline $\begin{array}{l}\text { Germani; Pierce } \\
\text { (1992) }\end{array}$ & $\begin{array}{l}24 \text { narrativas com cinco frases cada, vocabulário comum e estrutura sintática } \\
\text { relativamente simples. }\end{array}$ \\
\hline $\begin{array}{l}\text { Brennan; Worrall; } \\
\text { McKenna (2005) }\end{array}$ & $\begin{array}{l}90 \text { parágrafos indicados para crianças de } 5^{\mathrm{a}}, 6^{\mathrm{a}} \text { e } 7^{\mathrm{a}} \text { séries de acordo com o } \\
\text { índice Flesch. }\end{array}$ \\
\hline Dietz (2008) & $\begin{array}{l}\text { Três narrativas. } 1^{\mathrm{a}}-107 \text { palavras, } 10.7 \text { palavras por frase, } 3.9 \text { caracteres por } \\
\text { palavra e índices de leitura Ease e Flesch-Kincaid } 95.5 \text { e } 2.5 ; 2^{\mathrm{a}}-100 \text { palavras, } \\
\text { Dez palavras por sentença, } 4.2 \text { caracteres por palavra e índices de leitura Ease e } \\
\text { Flesch-Kincaid } 95.1 \text { e } 2.4 ; 3^{\mathrm{a}}-101 \text { palavras, } 10.1 \text { palavras por frase, } 3.8 \\
\text { caracteres por palavra e índices de leitura Ease e Flesch-Kincaid } 96.9 \text { e } 2.2 \text {. }\end{array}$ \\
\hline
\end{tabular}

Fonte: Elaboração própria

\section{Considerações finais}

O presente trabalho teve como intuito discutir o uso de narrativas como forma pertinente de avaliação da compreensão afásica. Para essa reflexão, foram trazidas considerações sobre as tarefas de compreensão de narrativas já utilizadas na literatura, bem como discutidos aspectos avaliados por essas tarefas, como os níveis macro- e 
microestruturais dos textos, a influência do contexto e a complexidade sintática. Também houve ressalvas sobre as baterias normalmente usadas para a avaliação afásica que contam com poucas atividades de compreensão de textos, somente tarefas com compreensão de palavras isoladas.

Dessa forma, no Brasil, há uma dependência dos testes traduzidos e dos parâmetros de avaliação internacionais, fazendo com que, muitas vezes, os contextos educacional, demográfico, cultural e linguístico da população brasileira sejam ignorados. As adaptações de testes para o contexto brasileiro são, de fato, um enorme desafio. Não se trata somente de traduzir para o português. Como já destacado, devem ser controladas as variáveis que se apresentam na adaptação de um teste, como frequência e categoria das palavras, extensão, dentre outras. Ainda, sabe-se que há restrições na administração de determinados testes de avaliação da linguagem, da comunicação na afasia, bem como os neuropsicológicos por linguistas ou fonoaudiólogos, fator que implica a necessidade de formação de equipes multidisciplinares para as pesquisas em geral.

\section{REFERÊNCIAS}

ADAM, J.-M. Le texte narratif. Paris: Nathan, 1985.

Cadre théorique d'une typologie séquentielle. Études de Linguistique Appliquée - textes, discours types et genres - E.L.A., n. 83, p. 6-18, 1991. $\overline{\text { Cortez, } 2008 .}$

. A linguística textual: introdução à análise textual dos discursos. São Paulo:

BARBEY, A. K.; COLOM, R.; GRAFMAN, J. Neural mechanisms of discourse comprehension: A human lesion study. Brain, v. 137, n. 1, p. 277-287, 2014.

BLOOME, D. Narrative discourse. In: GRAESSER, A.; GERNSBACHER, M. A.; GOLDMAN, S. Handbook of discourse processes. London: Lawrence Erlbaum Associates publishers, 2003. p. 287-393.

BRENNAN, A.; WORRALL, L.; MCKENNA, K. The relationship between specific features of aphasia-friendly written material and comprehension of written material for people with aphasia: An exploratory study. Aphasiology, v. 19, n. 8, p. 693-711, 2005.

BROOKSHIRE, R. H.; NICHOLAS, L. E. Comprehension of directly and indirectly stated main ideas and details in discourse by brain-damaged and non-brain-damaged listeners. Brain and language, v. 21, n. 1, p. 21-36, 1984.

Builders, 1993.

Discourse Comprehension Test. Tucson, Arizona: Communication Skill

CAPLAN, D.; EVANS, K. L. The effects of syntactic structure on discourse comprehension in patients with parsing impairments. Brain and Language, v. 39, n. 2, p. 206-234, 1990.

CHERNEY, L. R. Aphasia, alexia, and oral reading. Topics in stroke rehabilitation, v. 11, n. 1, p. 22-36, 2004.

Oral reading for language in aphasia (ORLA): evaluating the efficacy of computer-delivered therapy in chronic nonfluent aphasia. Topics in Stroke Rehabilitation. Nov-Dec, v. 17, n. 6, p. 423-31, 2010. 
CRUTCH, S.; WARRINGTON, E. Different patterns of spoken and written word comprehension deficit in aphasic stroke patients. Cognitive Neuropsychology, v. 28, n. 6, p. 414-434, 2011.

DALE, E.; CHALL, J. A Formula for Predicting Readability. Educational Research Bulletin, v. 27, n. 11, p. 20-28, 1948.

DEDE, G. Reading and listening in people with aphasia: Effects of syntactic complexity. American Journal of Speech-Language Pathology, v. 22, n. 4, p. 579-590, 2013.

DIETZ, A. R. Reading comprehension by people with chronic aphasia: A comparison of three levels of visuographic contextual support. Dissertation Abstracts International, B: Sciences and Engineering, v. 68, n. 10, p. 1053-1064, 2008.

DRONKERS, N. F. et al. Lesion analysis of the brain areas involved in language comprehension. Cognition, v. 92, n. 1-2, p. 145-177, 2004.

FARIAS, W. S. DE; DIJK, V. Compreensão e Resumo de Textos: Alguns Aspectos Teóricos e Experimentais, v. 1, p. 103-110, 2000.

FERSTL, E. C. et al. Assessment of story comprehension deficits after brain damage. Journal of clinical and experimental neuropsychology, v. 27, n. 3, p. 367-384, 2005.

The extended language network: a meta-analysis of neuroimaging studies on text comprehension. Human brain mapping, v. 29, n. 5, p. 581-593, 2008.

FERSTL, E. C.; GUTHKE, T.; VON CRAMON, D. Y. Text comprehension after brain injury: left prefrontal lesions affect inference processes. Neuropsychology, v. 16, n. 3, p. 292-308, 2002.

FERSTL, E. C.; VON CRAMON, D. Y. The role of coherence and cohesion in text comprehension: an event- related fMRI study. Brain Res.Cogn Brain Res., v. 11, n. 3, p. 325-340, 2001.

FLESCH, R. The art of readable writing. Harper: New York, 1948.

GERGEN, K. J.; GERGEN, M. M. Narrative and the Self as Relationship. Advances in Experimental Social Psychology, v. 21, n. C, p. 17-56, 1988.

GERMANI, M. J.; PIERCE, R. S. Contextual influences in reading comprehension in aphasia. Brain and Language, v. 42, n. 3, p. 308-319, 1992.

GLOSSER, G.; DESER, T. Patterns of discourse production among neurological patients with fluent language disorders. Brain and Language, v. 40, n. 1, p. 67-88, 1991.

GOODGLASS, H.; KAPLAN, E. The Assessment of Aphasia and Related Disorders. 3. ed. Philadelphia: Lea \& Febiger, 1995

HALLIDAY, M. A.; HASAN, R. Cohesion in English. London: Longman, 1976.

HALLOWELL, B.; CHAPEY, R. Introduction to language intervention strategies in adult aphasia. Language intervention strategies in aphasia and related neurogenic communication disorders, n. January, p. 3-19, 2008.

HOWARD, D. A. V. I. D. Cognitive neuropsychology and aphasia therapy: The case of word retrieval. Acquired neurogenic communication disorders: A clinical perspective, p. 76-99, 2000. 
HUBER, W. Text comprehension and production in aphasia: Analysis in terms of microand macrostructure. In: JOANETTE, Y., BROWNELL, H. H. (Eds.). Discourse ability and brain damage: Theoretical and empirical perspective. New York: Springer-Verlag, 1990. p. 154-179.

JERÔNIMO, G. M. Investigando o processamento de narrativas na lesão cerebral de hemisfério direito. 2012. 135 f. Dissertação (Mestrado em Linguística) - Pontifícia Universidade Católica do Rio Grande do Sul, Porto Alegre, 2012.

Produção de narrativas orais no envelhecimento sadio, no comprometimento cognitivo leve e na doença de Alzheimer e sua relação com construtos cognitivos e escolaridade. 2016. 201 f. Tese (Doutorado em Linguística) - Pontifícia Universidade Católica do Rio Grande do Sul, Porto Alegre, 2016.

KAY, J.; LESSER, R.; COLTHEART, M. Psycholinguistic Assessments of Language Processing in Aphasia. (PALPA). Hove: Lawrence Erlbaum Associated Ltd, 1992.

KERTESZ, A. The Western Aphasia Battery-Revised. New York: Grune \& Stratton, 2007.

KUMAR, S.; GOSWAMI, S. P. Paragraph comprehension deficits in hindi speaking persons with aphasia in different modalities: a preliminary study, v. 31, n. 1985, 2012.

$\mathrm{LABOV}, \mathrm{W}$. The transformation of experience in narrative syntax. Language in the inner city: studies in the black English vernacular. Philadelphia: search papers, 1972. p. 354396.

LIMA, F. A. F. de. Correlação entre os achados de uma avaliação de linguagem e fala no leito e o território vascular encefálico em pacientes vítimas de AVE em estado agudo. 2009. 40 f. Trabalho de conclusão de curso (Fonoaudiologia) - Faculdade de Medicina, Universidade Federal de Minas Gerais, Belo Horizonte, 2009.

LOTT, S. N.; FRIEDMAN, R. B. Can treatment for pure alexia improve letter-by-letter reading speed without sacrificing accuracy? Brain and language, v. 67, n. 3, p. 188-201, 1999.

MAGUIRE, E. A et al. Navigation-related structural change in the hippocampi of taxi drivers. Proceedings of the National Academy of Sciences of the United States of America, v. 97 , n. 8, p. 4398-4403, 2000.

MANSUR, L. L. et al. Descriptive study of 192 adults with speech and language disturbances. Sao Paulo Medical Journal/Revista Paulista de Medicina, v. 120, n. 6, p. 170-174, 2002.

MARCUSCHI, L. A. Produção textual, análise de gêneros e compreensão. São Paulo: Parábola, 2008.

Editorial, 2014.

Linguística de texto: o que é e como se faz? 3. ed. São Paulo: Parábola

MCKEVITT, C. et al. Self-reported long-term needs after stroke. Stroke, v. 42, n. 5, p. 1398-1403, 2011.

NOVAES-PINTO, R. A contribuição do estudo discursivo para uma análise crítica das categorias clínicas. 1999. 157 f. Tese (Doutorado em Linguística) - Instituto de Estudos da Linguagem, Universidade Estadual de Campinas, Campinas, 1999. 
ORTIZ, K. Z. Distúrbios Neurológicos Adquiridos: Linguagem e Cognição. 2. ed. Barueri: Manole, 2010.

SPRINGER, L. Therapeutic approaches in aphasia rehabilitation. In: STEEMER, B.; WHITAKER, H. Handbook of the neuroscience of language. USA: Academic Press, 2008. p. 397-405.

ULATOWSKA, H. K. et al. Neurolinguistic approaches to aphasia. Seminars in Speech, Language and Hearing, 2, p. 269-281, 1981.

ULATOWSKA, H. K.; CHAPMAN, S. Neurolinguistics and aging. In: RIPICH, D. N. Geriatric Communication Disorders. Austin, Texas: Pro-Ed, 1991. p. 21-37.

Macrostructure and inferential processing in discourse of aphasic patients. Psychology of Language and..., v. 3, n. 2, p. 3-20, 1999.

WEBSTER, J. et al. Text level reading comprehension in aphasia: What do we know about therapy and what do we need to know? Aphasiology, v. 27, n. 11, p. 1362-1380, 2013.

WEGNER, M. L.; BROOKSHIRE, R. H.; NICHOLAS, L. E. Comprehension of main ideas and details in coherent and noncoherent discourse by aphasic and nonaphasic listeners. Brain and Language, v. 21, n. 1, p. 37-51, 1984.

WIT, E. C.; GILLETTE, M. What is linguistic redundancy? Disponível em: $<$ http://www.math.rug.nl/ ernst/linguistics/redundancy3.pdf>. Acesso em: 5 mai. 2016.

$\mathrm{XU}$, J. et al. Language in context: Emergent features of word, sentence, and narrative comprehension. NeuroImage, v. 25, n. 3, p. 1002-1015, 2005.

Recebido em: 09/08/2016

Aprovado em: 10/01/2017 